\title{
Analysis of Different Energy Storage Technologies for Microgrids Energy Management
}

\author{
Darío Benavides ${ }^{1,2}$, Paúl Arévalo ${ }^{2,3}$, Luis G. Gonzalez ${ }^{2}$ and José A. Aguado ${ }^{1 *}$ \\ ${ }^{1}$ University of Malaga, Electrical Engineering Department, 29590 Malaga, Spain \\ ${ }^{2}$ University of Cuenca, Department of Electrical Engineering, Electronics and Telecommunications, 010107 Cuenca, Ecuador \\ ${ }^{3}$ University of Jaen, Electrical Engineering Department, 23009 Jaen, Spain
}

\begin{abstract}
The importance of energy storage systems is increasing in microgrids energy management. In this study, an analysis is carried out for different types of energy storage technologies commonly used in the energy storage systems of a microgrid, such as: lead acid batteries, lithium ion batteries, redox vanadium flux batteries and supercapacitors. In this work, it is analyzed the process of charging and discharging (slow and fast) in these systems, the calculation of energy efficiency, performance and energy supplied under different load levels, in its normal operating conditions and installed power capacity is developed. The results allow us to choose the optimal conditions of charge and discharge at different levels of reference power, analyzing the strengths and weaknesses of the characteristics of each storage system within a microgrid.
\end{abstract}

\section{Introduction}

The representation of Micro-Grid (MG) assumes a set of loads and generation micro-sources, which, functions as a single controllable system that provides energy in a local area. This concept provides a new paradigm to define the operation of Distributed Generation (DG). An autonomous MG with Renewable Energy sources (RE) and Energy Storage Systems (ESS) could be an attractive solution to address the electricity needed in in remote areas [1], [2], [3]. The EES refers to the process of converting energy from one form to another storable and being able to reserve it in various media; then the stored energy can be converted back into electrical energy when required [4]. Therefore, the ESS in a MG is one of the main solutions when there are shortages of power generation to be able to balance the demand with the generation. In addition, the power fluctuations generated by the ER sources deteriorate the power quality of the electricity grid and cause instability, therefore, the ESS is an effective technique to smooth the fluctuation of energy [5].

Existing ESS technologies face challenges in energy storage, due to limitations of storing large amounts of energy for a long period of time and various other problems, such as: charge/discharge, security, reliability, size, cost, cycle of life, etc. Therefore, an advanced ESS is required with respect to capacity, protection, control interface, power management and features to improve ESS performance in MG applications [1], [4].

The ESS is generally composed of an energy storage device with a bi-directional power converter with appropriate control for the grid integration [6]. The largerscale ESS are more appropriate for the generation and higher voltage levels of the power grid, while the smaller- scale ESS can serve various purposes at the lower voltage distribution level and for other important applications. However, the optimal management of ESS for efficient MG operation remains a challenge in smart grids, some ESS control methods are detailed in [7].

In this study, an analysis is made of the different types of energy storage commonly used in the ESS of a MG, such as batteries based on: lead acid, lithium ion, redox vanadium flux batteries, and supercapacitors. In the analysis, the process of charging and discharging (slow and fast) in these systems, the calculation of energy efficiency, performance and energy supplied under different load levels, in its normal operating conditions and installed power capacity is developed. Regarding the subject, there are several studies related to the ESS, but most of them are related to the simulation, so the main contribution of this paper is on the advantages and disadvantages of each ESS system based on experiences applied in a MG.

\section{ESS Application in Microgrids}

The operation of future MGs will require the use of ESS that employ power electronics converters with advanced power management capabilities. Although there are currently several ways to store electrical energy, not only does it depend on it to obtain a reliable grid, it is necessary to soften and regulate power-demand spikes that exist in load variations of the electrical system [8]. An optimal ESS ensures low energy cost with adequate sizing during the project planning stage. In addition, it is a requirement to consider the density of power and energy that will result in the necessary physical space [7]. Some related

Corresponding author: jaguado@uma.es 
applications of the integration of ESS in MG to minimize the use of diesel fuels, through control algorithms, and stochastic studies analyze the availability of generation and storage together with the technical-economic aspects, which allow the MG operator to identify solutions optimal and feasible planning [9], [10]. Although, it should be considered that each control strategy is different and tends towards application oriented that may not be applicable to other systems [11]. An autonomous $\mathrm{MG}$ based on photovoltaic energy with ESS could be a promising solution to energy isolated communities [11], [3]. However, photovoltaic energy is produced at a very variable power level, periods of low irradiance can be detected, and capacity will depend on the installation characteristics, its location, the season and the presence of cloudiness in the area [12], [8]. These factors are some problems mostly solved with the use of ESS within the MG. In addition, ESS in Microgrids PV also helps in reactive power compensation as well as suppression of voltage fluctuation and flickering [11]. An example of the reduction of emissions with the integration of ESS in the MG and the optimization of systems based on monitoring the state of charge and costs in generation [13], [3]. These are some case studies that demonstrate the importance of ESS in the energy management of a MG

Figure 1 shows a classic demand model and the integration of renewable generation sources such as photovoltaic and wind solar in a microgrid, where its application of ESS is of great importance to achieve a correct performance of all the elements of the MG. The results of the simulation in a MG with the short-term overload of the ESS in the primary frequency control, showed that the use of the battery overload feature allows a small size ESS and able to respond quickly to the fault of balance between generation and demand, with only $20 \%$ of the total capacity designed, in addition to using only a percentage of (2-4\%) of the SoC of the ESS demonstrating its effectiveness [14].

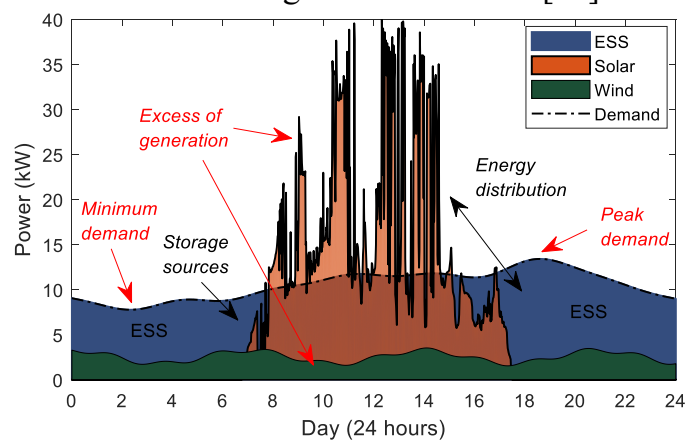

Fig. 1. Application of an ESS in a Microgrid

The objective of the ESS in energy management is to take advantage of the strength of different ESS devices to compensate for the weaknesses of each of the storage element [11]. For an application to be carried out effectively, it is crucial that the correct storage technology is determined. In this case, the excess generation of solar and wind power during the hours of the day 6:00-18:00. It is possible to store it in an ESS for a certain time. In other words, the ESS can absorb excess renewable generation, without threatening the safe operation of the electricity grid, and can be discharged during periods of increased demand to relieve part of the load [7]. This would allow to supply the energy demand partially or totally during the contingency, considering that each element that integrates the ESS makes a balanced and actively controlled contribution.

\section{ESS Microgrid - Case study}

The MG under study is located at the Balzay Technology Campus of the University of Cuenca in Ecuador, it consists of several ESS battery technologies such as: Lead Acid, Lithium Ion, Vanadium Redox and Supercapacitors integrated with equipment that allows the double current flow of the Inverter/charger to and from the public electricity grid, by means of a SCADA system, it allows the power parameters $[\mathrm{kW}]$ to be sent to determine the equipment recharge or discharge operations [15]. In Figure 2 , the ESS elements of the case study are observed in this article and the characteristics of each system are detailed in Table 1:

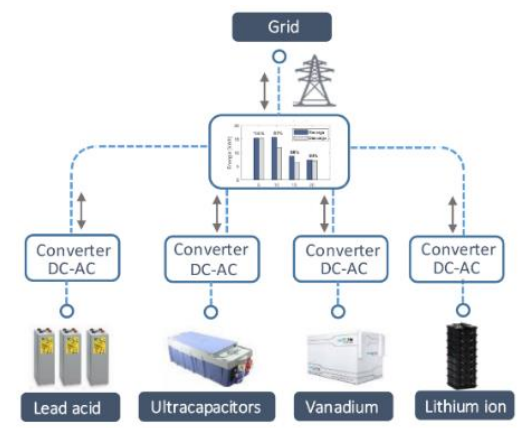

Fig. 2. Microgrid Energy Storage Systems (ESS)

Table 1. ESS features of the Microgrid under study

\begin{tabular}{|l|c|c|c|c|}
\hline \multicolumn{1}{|c|}{ Type ESS } & Model & $\begin{array}{c}\text { Cells } / \\
\text { Modules }\end{array}$ & $\begin{array}{c}\text { Operating } \\
\text { voltage }\end{array}$ & Energy \\
\hline $\begin{array}{l}\text { Acid Lead } \\
\text { Battery }\end{array}$ & $\begin{array}{c}\text { A600/ } \\
\text { Solar }\end{array}$ & 84 cells & $168 \mathrm{~V}$ & $15 \mathrm{kWh}$ \\
\hline $\begin{array}{l}\text { Lithium Ion } \\
\text { Battery }\end{array}$ & $\begin{array}{c}\text { Samsung } \\
\text { ELPT392 } \\
-0002\end{array}$ & 11 cells & $642 \mathrm{~V}$ & $44 \mathrm{kWh}$ \\
\hline $\begin{array}{l}\text { Vanadium } \\
\text { Redox Flow } \\
\text { Battery }\end{array}$ & $\begin{array}{c}\text { Cellcube } \\
\text { FB 20- } \\
100\end{array}$ & $\begin{array}{c}12 \\
\text { modules }\end{array}$ & $48 \mathrm{~V}$ & $100 \mathrm{kWh}$ \\
\hline $\begin{array}{l}\text { Super- } \\
\text { capacitors }\end{array}$ & $\begin{array}{c}\text { Maxwell } \\
\text { BMOD- } \\
0130\end{array}$ & 10 cells & $560 \mathrm{~V}$ & $0.4 \mathrm{kWh}$ \\
\hline
\end{tabular}

\subsection{Capacity and State of Charge of the Batteries}

The optimal use of ESS systems depends not only on the electrical grid topology, limitations and purpose, but also on the state of charge (SoC) of the ESS [16]. Therefore, battery capacity is considered an important parameter in the selection of a storage device. The capacity of a battery can be defined as the total amount of electrical charges that can be delivered in a single discharge per cell. On the other hand, the SoC can be described as the ratio between the remaining capacity and the nominal capacity of the battery. Equation (1) represents the variation of SoC (dSoC) that depends on time and capacity $C_{i}$ [2]. 


$$
d \operatorname{SoC}=\frac{i d t}{C_{i}}=S o C-\int \frac{i d t}{C_{i}}
$$

The different operating requirements in a microgrid lead to the use of ESS under different conditions of fast and slow charging, depending on their availability. Therefore, it is convenient to restrict the ESS SoC to achieve a predefined objective within a given time frame and to establish an adequate balance in energy management [17].

\subsection{Tests on Lead Acid Battery}

In the processes of charging and discharging the batteries through the charger/inverter (AC/DC-DC/AC), the consumption and delivery of energy to the public electricity grid was carried out. During the test period, power values referenced to the installed capacity and specifications of the normal operation established by the manufacturer were used. Figure 3 shows the process of charging and discharging lead acid batteries with constant power values of: $5 \mathrm{~kW}, 10 \mathrm{~kW}, 15 \mathrm{~kW}, 20 \mathrm{~kW}$, respectively at a discharge depth $S O C_{P B}$ of $70 \%$, under an average temperature of $20^{\circ} \mathrm{C}$. For energy efficiency it was calculated by means of Equation 2 established by the manufacturer. It should be noted that for values less than $5 \mathrm{~kW}$ and greater than $20 \mathrm{~kW}$ the system regulates itself during the state of charge process with a current less than $16 \mathrm{~A}$ or greater than $140 \mathrm{~A}$ respectively.

$$
\eta_{W h}(\%)=\frac{A h_{d} \cdot \operatorname{Vprom}_{d}}{A h_{c} \cdot \operatorname{Vprom}_{c}}
$$

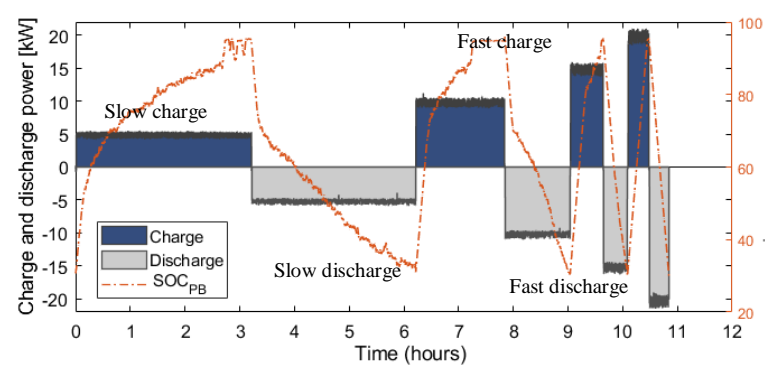

Fig. 3. Acid lead battery charge and discharge process

In Figure $4 \mathrm{a}$, the hours of charging and discharging the batteries under different power values are observed, considering a constant power of $5 \mathrm{~kW}, 10 \mathrm{~kW}, 15 \mathrm{~kW}$ and $20 \mathrm{~kW}$ for charging periods of $3.20 \mathrm{~h}, 1.68 \mathrm{~h}, 0.6 \mathrm{~h}$ and $0.38 \mathrm{~h}$ respectively, similarly periods of $3 \mathrm{~h}, 1.18 \mathrm{~h}, 0.45 \mathrm{~h}$ and $0.35 \mathrm{~h}$ for energy discharge processes. The energy consumed during the recharge and discharge process is presented in Figure 4b with their respective efficiency indicators during the testing process.
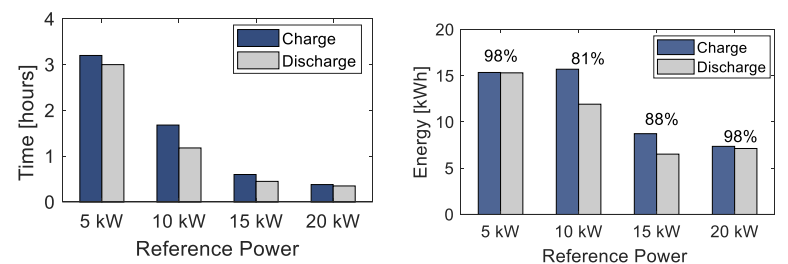

Fig. 4. (a) Charge-discharge time (b) Charge-discharge energy acid lead batteries

\subsection{Tests on Lithium-Ion Battery}

An optimal estimation of the SoC of the battery is useful in order to improve the life of the battery, in [18] a method is presented by using a Kalman filter. In the processes of charging and discharging the batteries through the AC/DC and $\mathrm{DC} / \mathrm{AC}$ charger/inverter, the consumption and delivery of energy to the public electricity grid was carried out. During the test period, power values were used, referenced to the installed capacity and specifications of the normal operation established by the manufacturer. Figure 5 shows the process of charging and discharging lead acid batteries with constant power values of: $5 \mathrm{~kW}$, $10 \mathrm{~kW}, 15 \mathrm{~kW}, 20 \mathrm{~kW}$, respectively at a discharge depth $S O C_{L I}$ of $70 \%$, under an average temperature of $20^{\circ} \mathrm{C}$.

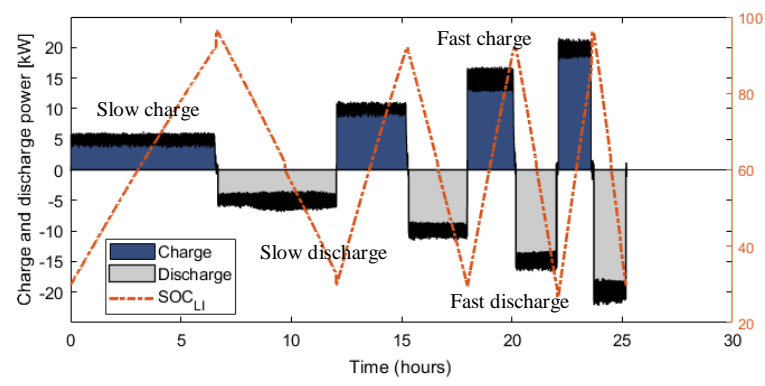

Fig. 5. Lithium ion battery charge and discharge process

Figure 6a shows the hours of charging and discharging the batteries under different power values, considering a constant power of $5 \mathrm{~kW}, 10 \mathrm{~kW}, 15 \mathrm{~kW}$ and $20 \mathrm{~kW}$ for charging periods of $6.36 \mathrm{~h}, 3.13 \mathrm{~h}, 2.0 \mathrm{~h}$ and $1.46 \mathrm{~h}$ respectively, similarly periods of $5.25 \mathrm{~h}, 2.63 \mathrm{~h}, 1.52 \mathrm{~h}$ and $1.33 \mathrm{~h}$ for energy discharge processes. The energy consumed during the charging and discharging process is presented in Figure $6 \mathrm{~b}$ with their respective efficiency indicators during the testing process.
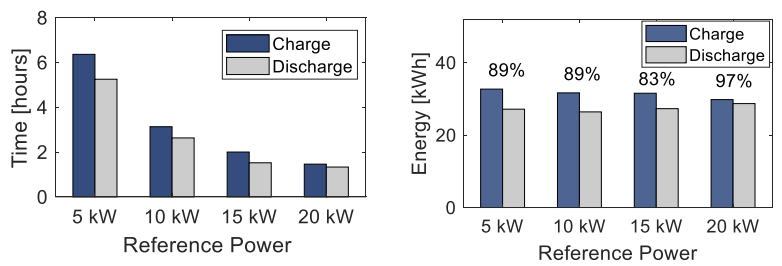

Fig. 6. (a) Charge-discharge time (b) Charge-discharge energy lithium ion batteries

\subsection{Tests on Vanadium Redox Flow Battery}

The VRB power converters are required to adapt the various voltages within the system, the battery voltage differs from the public grid voltage or the charging voltages [19]. In the case of study, the processes of charging and discharging the batteries were carried out through the $\mathrm{AC} / \mathrm{DC}$ and $\mathrm{DC} / \mathrm{AC}$ charger/inverter with the delivery and consumption of energy from the public electricity grid. The overall energy efficiency of the system varies significantly under different operating conditions. Therefore, it is vital to evaluate and compare the efficiency of the system under different scenarios [19]. During the test period, power values were used, referenced to the installed capacity and specifications of the normal operation established by the manufacturer. Figure 7 shows the process of charging and discharging VRB batteries 
with constant power values of: $5 \mathrm{~kW}, 10 \mathrm{~kW}, 15 \mathrm{~kW}, 20 \mathrm{~kW}$, respectively at a discharge depth $S O C_{V R B}$ of $70 \%$, under an average temperature of $20^{\circ} \mathrm{C}$. This process allows the battery to be charged under a constant current throughout the process, and to operate the electrolyte pumps at a constant low speed at low SoC and high speed at high SoC, a similar example in [17]. Energy efficiency was calculated by means of Equation 3, basically defined as the ratio between the energy supplied by the battery during discharge $\int P_{V R B, d}(t) d t$ and the energy supplied during charging $\int\left|P_{V R B, C}\right|(t) d t$ [19]. It should be noted that for values greater than $20 \mathrm{~kW}$ the system regulates itself during its charging process.

$$
\eta_{W h}(\%)=\frac{\int P_{V R B, d}(t) d t}{\int\left|P_{V R B, c}\right|(t) d t}
$$

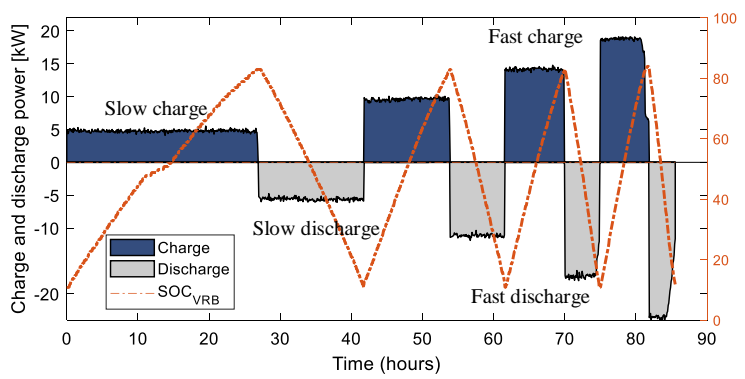

Fig. 7. Vanadium Redox battery charge and discharge process

Figure 8 a shows the hours of charging and discharging the batteries under different power values, considering a constant power of $5 \mathrm{~kW}, 10 \mathrm{~kW}, 15 \mathrm{~kW}$ and $20 \mathrm{~kW}$ for charging periods of $27 \mathrm{~h}, 12 \mathrm{~h}, 7.5 \mathrm{~h}$ and $7 \mathrm{~h}$ respectively, in the same way $15 \mathrm{~h}, 7.5 \mathrm{~h}, 5 \mathrm{~h}$ and $5 \mathrm{~h}$ periods for energy discharge processes. The energy consumed during the charging and discharging process is presented in Figure $8 \mathrm{~b}$ with their respective efficiency indicators during the testing process.
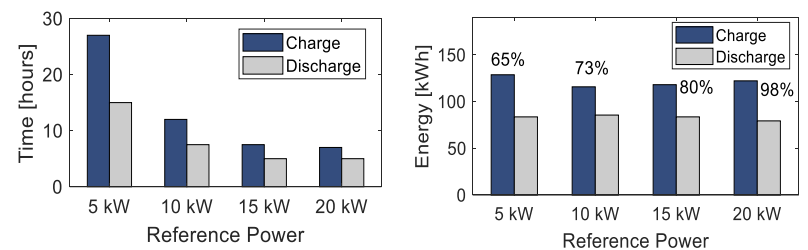

Fig. 8. (a) Charge-discharge time (b) Charge-discharge energy vanadium redox batteries

\subsection{Tests on Supercapacitors}

An ESS that integrates the supercapacitor includes a bidirectional DC-DC converter and an inverter connected to the electricity grid. Together this system is able to guarantee the quality of energy in a short period of time. In [5] the control strategies of both the DC-DC bidirectional converter connected to the electricity grid are proposed to guarantee optimal charge and discharge operations within ESS. The effective use of the ultracapacitor for energy management requires a thorough analysis of energy storage and delivery efficiency [20]. Figure 9 shows charge and discharge process with constant power values of: $5 \mathrm{~kW}, 10 \mathrm{~kW}, 20 \mathrm{~kW}, 30 \mathrm{~kW}$, respectively at a discharge depth $S O C_{S C}$ of $90 \%$, under an average temperature of $20^{\circ} \mathrm{C}$.

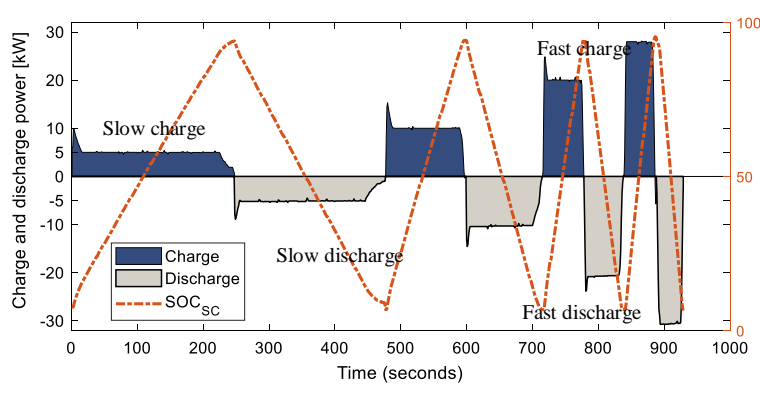

Fig. 9. Supercapacitors charge and discharge process

The energetic efficiency of supercapacitors $\eta_{S C}(\%)$ can be calculated using Equation 4 [20], which relates the output energy during the discharge time $E_{\text {out }}\left(T_{d}\right)$ and input power during charge time $E_{\text {in }}\left(T_{C}\right)$ :

$$
\begin{gathered}
\eta_{S C}(\%)=\frac{E_{\text {out }}\left(T_{d}\right)}{E_{\text {in }}\left(T_{C}\right)} \\
E_{\text {out }}\left(T_{d}\right)=\int_{T_{C}}^{T_{d}} P_{\text {out }}(t) \cdot d t ; E_{\text {in }}\left(T_{c}\right) \\
=\int_{0}^{T_{C}} P_{\text {in }}(t) \cdot d t,
\end{gathered}
$$

Figure 10a shows the hours of charging and discharging the batteries under different power values, considering a constant power of $5 \mathrm{~kW}, 10 \mathrm{~kW}, 20 \mathrm{~kW}$ and $30 \mathrm{~kW}$ for recharge periods of $367 \mathrm{~s}, 170 \mathrm{~s}, 88 \mathrm{~s}$ and $62 \mathrm{~s}$ respectively, in the same way periods of $317 \mathrm{~s}, 135 \mathrm{~s}, 73 \mathrm{~s}$ and $42 \mathrm{~s}$ for energy discharge processes. The energy consumed during the charge and discharge process is presented in Figure 10b with their respective efficiency indicators during the testing process.
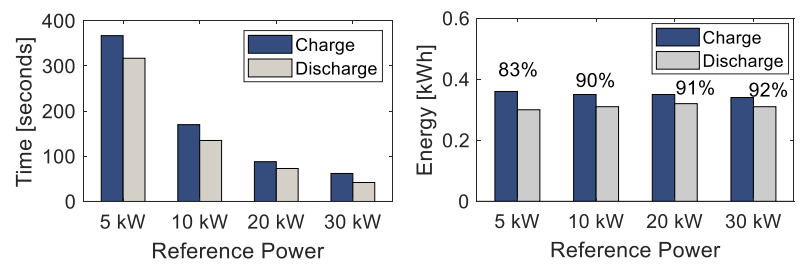

Fig. 10. (a) Charge-discharge time (b) Charge-discharge energy supercapacitors

\section{Results and Discussion}

The results obtained have demonstrated the different characteristics that each ESS has in experimental tests of different reference power levels, so it is possible to determine the strengths and weaknesses of each ESS for the optimal management of a MG. One way to proceed in the selection process is to create a comparative table with the necessary characteristics and record the values of the storage technologies considered for each case. This comparison will eventually lead to the selection of the appropriate ESS for the application considered [7].

In Figure 11a, it presents the results obtained from Equation 2 for lead acid batteries under different reference power levels, with which we can see what type of batteries are ideal for slow discharge processes less than $7 \mathrm{~kW}$, regardless of load levels that are carried out. However, it is important to consider the number of charge and 
discharge cycles, therefore it would be convenient to carry out fast and slow discharges.

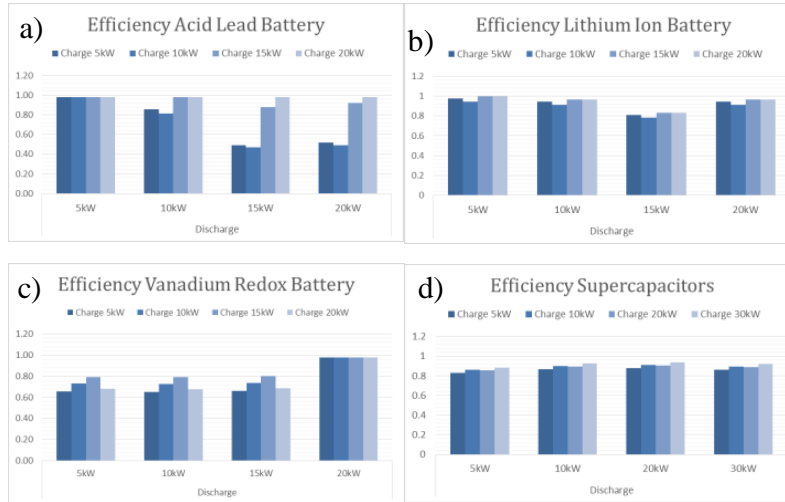

Fig. 11. Energy efficiency under different charge and discharge conditions (a) Acid Lead Battery, (b) Lithium Ion, (c) Vanadium Redox Battery, (d) supercapacitors.

Lithium-ion batteries demonstrate similar levels in terms of the performance of each charge and discharge performed, as shown in Figure 11b. Unlike Lead Acid batteries, lithium-ion batteries have better efficiency at different power levels, maintaining similar characteristics in each case. In the same way it is important to consider the number of cycles of loads and discharges, it could guarantee slow charges and discharges less than $10 \mathrm{~kW}$ and greater than $20 \mathrm{~kW}$. In Figure $11 \mathrm{c}$, presents the results made in redox vanadium batteries, we can observe the characteristics of charges and discharges under different power levels. In this case it has proved potentially useful for fast high-power discharges around $20 \mathrm{~kW}$, as far as the load levels can be maintained at any level. This type of batteries when considered with a practically unlimited recharge and discharge system due to its mechanical and electrochemical mechanisms, it is possible to combine with lead acid and lithium ion batteries to balance an ESS in the best way.

Finally, in the case of supercapacitors as well as redox vanadium batteries have the advantage of virtually unlimited cycles in charges and discharges. It is possible to determine the reference power at any level without significantly losing efficiency (See Fig. 11d). However, the autonomy time is relatively short (only a few minutes). This storage system is ideal for reducing or mitigating large power variations of intermittent power generation systems such as photovoltaic or wind, where it is possible to deliver large amounts of power for a short period of time.

\section{Conclusions}

In this article, the efficiency tests on lead acid batteries, lithium ions, vanadium redox and supercapacitors, corresponding to the ESS of a MG were analyzed.

The characteristics of each system, as it has been observed, depend on several factors. However, the energy efficiency has been analyzed based on the equations presented and the results of the experimental tests.
The processes of the batteries have been tested for power values of $5 \mathrm{~kW}, 10 \mathrm{~kW}, 15 \mathrm{~kW}$ and $20 \mathrm{~kW}$, based on the characteristics of the normal operation of the batteries. In the case of supercapacitors, the reference power values have been modified to $5 \mathrm{~kW}, 10 \mathrm{~kW}, 20 \mathrm{~kW}$ and $30 \mathrm{~kW}$ in order to take advantage of this system for high powers.

From the experimental results, it can be seen that lead acid batteries are ideal for slow discharging processes, regardless of charge power levels. On the contrary, redox vanadium batteries have shown better results in fast discharges, regardless of charge levels.

In the case of lithium-ion batteries, it offers a similarity in slow discharges less than $10 \mathrm{~kW}$ and greater than $20 \mathrm{~kW}$, which determines a better performance in the extreme points.

Finally, supercapacitors, in this case have determined that they can be discharged or charged under different power levels, without greatly affecting their efficiency.

\section{References}

[1] M. Faisal, M. A. Hannan, P. J. Ker, A. Hussain, M. Bin Mansor, and F. Blaabjerg, "Review of energy storage system technologies in microgrid applications: Issues and challenges," IEEE Access, vol. 6. Institute of Electrical and Electronics Engineers Inc., pp. 3514335164, 26-May-2018.

[2] A. K. Rohit, K. P. Devi, and S. Rangnekar, "An overview of energy storage and its importance in Indian renewable energy sector: Part I - Technologies and Comparison," Journal of Energy Storage, vol. 13. Elsevier Ltd, pp. 10-23, 01-Oct-2017.

[3] M. R. Aghamohammadi and H. Abdolahinia, "A new approach for optimal sizing of battery energy storage system for primary frequency control of islanded Microgrid," Int. J. Electr. Power Energy Syst., vol. 54, pp. 325-333, 2014.

[4] X. Luo, J. Wang, M. Dooner, and J. Clarke, “Overview of current development in electrical energy storage technologies and the application potential in power system operation," Appl. Energy, vol. 137, pp. 511536, 2015.

[5] T. W. Chun, H. G. Kim, and E. C. Nho, "Charging and discharging strategies of grid-connected supercapacitor energy storage systems," in Proceedings of the IEEE International Conference on Industrial Technology, 2018, vol. 2018-Febru, pp. 1743-1747.

[6] J. Pegueroles-Queralt, F. D. Bianchi, and O. GomisBellmunt, "Control of a lithium-ion battery storage system for microgrid applications," J. Power Sources, vol. 272, pp. 531-540, Dec. 2014.

[7] M. Katsanevakis, R. A. Stewart, and J. Lu, "Aggregated applications and benefits of energy storage systems with application-specific control methods: A review," Renewable and Sustainable Energy Reviews, vol. 75. Elsevier Ltd, pp. 719-741, 2017.

[8] D. Álvaro, R. Arranz, and J. A. Aguado, "Sizing and 
operation of hybrid energy storage systems to perform ramp-rate control in PV power plants," Int. J. Electr. Power Energy Syst., vol. 107, pp. 589-596, May 2019.

[9] K. Thirugnanam, S. K. Kerk, C. Yuen, N. Liu, and M. Zhang, "Energy Management for Renewable Microgrid in Reducing Diesel Generators Usage with Multiple Types of Battery," IEEE Trans. Ind. Electron., vol. 65, no. 8, pp. 6772-6786, Aug. 2018.

[10] J. Qiu, J. Zhao, H. Yang, D. Wang, and Z. Y. Dong, "Planning of solar photovoltaics, battery energy storage system and gas micro turbine for coupled micro energy grids," Appl. Energy, vol. 219, pp. 361-369, Jun. 2018.

[11] W. Jing, C. H. Lai, W. S. H. Wong, and M. L. D. Wong, "Dynamic power allocation of batterysupercapacitor hybrid energy storage for standalone PV microgrid applications," Sustain. Energy Technol. Assessments, vol. 22, pp. 55-64, Aug. 2017.

[12] J. M. González, J. A. Domínguez, J. M. Ruiz, and C. Alonso, "Ultracapacitors utilization to improve the efficiency of photovoltaic installations," Sol. Energy, vol. 134, pp. 484-493, Sep. 2016.

[13] H. Moradi, M. Esfahanian, A. Abtahi, and A. Zilouchian, "Optimization and energy management of a standalone hybrid microgrid in the presence of battery storage system," Energy, vol. 147, pp. 226238, Mar. 2018.

[14] K. Belmokhtar, H. Ibrahim, Z. Féger, and M. Ghandour, "Charge Equalization Systems for Serial Valve Regulated Lead-Acid (VRLA) Connected Batteries in Hybrid Power Systems Applications," in
Energy Procedia, 2016, vol. 99, pp. 277-284.

[15] J. L. Espinoza, L. G. Gonzalez, and R. Sempertegui, "Micro grid laboratory as a tool for research on nonconventional energy sources in Ecuador," in 2017 IEEE International Autumn Meeting on Power, Electronics and Computing, ROPEC 2017, 2018, vol. 2018-Janua, pp. 1-7.

[16] T. Morstyn, B. Hredzak, R. P. Aguilera, and V. G. Agelidis, "Model Predictive Control for Distributed Microgrid Battery Energy Storage Systems," IEEE Trans. Control Syst. Technol., vol. 26, no. 3, pp. 1107 1114, May 2018.

[17] Y. Li, X. Zhang, J. Bao, and M. Skyllas-Kazacos, "Studies on optimal charging conditions for vanadium redox flow batteries," J. Energy Storage, vol. 11, pp. 191-199, Jun. 2017.

[18] Y. Zhao, J. Xu, X. Wang, and X. Mei, "The Adaptive Fading Extended Kalman Filter SOC Estimation Method for Lithium-ion Batteries," in Energy Procedia, 2018, vol. 145, pp. 357-362.

[19] C. Blanc and A. Rufer, "Optimization of the operating point of a vanadium redox flow battery," in 2009 IEEE Energy Conversion Congress and Exposition, ECCE 2009, 2009, pp. 2600-2605.

[20] M. R. Kumar, S. Ghosh, and S. Das, "Chargedischarge energy efficiency analysis of ultracapacitor with fractional-order dynamics using hybrid optimization and its experimental validation," $A E U$ Int. J. Electron. Commun., vol. 78, pp. 274-280, Aug. 2017. 